\title{
Research of Adsorption on PCBs: Isotherm Modeling and Influencing Factors
}

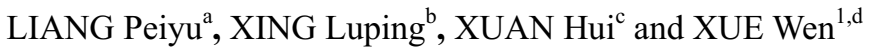 \\ College of Urban and Environmental Science Tianjin Normal University, Tianjin 300387, China \\ arambleinthecloud@126.com, b1195727910@qq.com \\ '857599801@qq.com, ${ }^{\mathrm{d}} 747655708 @ q q . c o m$
}

\begin{abstract}
PCBs are a group of persistent organic pollutants (POPs) in the environment. Adsorption behavior of PCBs has obtained great attention affecting the degradation, mobility activities. In this paper, adsorption process was studied systematically to figure out the model of adsorption, adsorption mechanism and the influencing factors, which will provides the theoretical basis for further research.
\end{abstract}

\section{Introduction}

The properties of PCBs (PCBs) are stable, which have carcinogenicity-mutagenicity teratogenicity effects. PCBs became a research hotspot for its serious environmental pollutions ${ }^{[1,2]}$.PCBs were widely used for transformers, fire retardant agent, battery, fuel dispersant, heat carrier, pesticide delay effect agent and so on. At present, there are still $2.1 \times 10^{3} \mathrm{t}$ PCBs in surface soil ${ }^{[3,4]}$. Adsorption behaviors of PCBs influences its migration, transformation, distribution, biodegradability and biological availability ${ }^{[5,6,7]}$.So exploring the PCBs' adsorption behaviors deeply has a great significance in researching the PCBs' migrating rules in environmental behaviors.

\section{Progress in the Study of Adsorption of PCBs}

The sources of adsorbents which have adsorption effects on PCBs are abundant. Different adsorption materials have different effects on the adsorption property of $\mathrm{PCBs}^{[8-23]}$. PCBs' adsorption kinetics most belong to first-order kinetics model and second-order kinetics model .From the analysis of the different adsorption materials' adsorption isotherm models, we can conclude that PCBs' adsorptions conform to Langmuir and Freundlich adsorption isotherm models.

\footnotetext{
*Corresponding author: rambleinthecloud@126.com
} 


\section{Mechanism and Influence Factors of Adsorption of PCBs}

\subsection{Adsorption mechanism analysis}

\subsubsection{Conjugate reaction}

4, 4'-DCB was able to form hydrogen bonds and electron donor acceptance potentials with the functional groups of Chitosan on the surface of the attapulgite. 4, 4'-DCB can be conjugated with hydroxyl and amino groups on the chitosan chains and then enhanced adsorption efficiency of 4, 4'-DCB by modified attapulgite. The isothermal adsorption line can be approximated as a straight line ${ }^{[8]}$.

\subsubsection{Physical and chemical adsorption}

Dominant mechanism is surface adsorption of organic compounds by soil. There are two types of absorption. One is the physical absorption which is mainly functioned van der waals force, another is chemical adsorptions which are functioned by dipole bond, hydrogen bond and coordination bond ${ }^{[8]}$.

\subsubsection{Freundlich adsorption}

The behavior of adsorption of PCBs can be well described. The multi molecular layer, complex and heterogeneous adsorption model are the main forms. Exponential values of equation of $\mathrm{n}$ are less than one. The whole adsorption process is nonlinear ${ }^{[9,10,29] \text {. }}$

\subsubsection{Langmuir adsorption}

It is essentially monolayer adsorption. The adsorption processes include fast adsorption and slow adsorption ${ }^{[8,11,15,17,29]}$. When the organic carbon content increase, Langumuir adsorption is the main method ${ }^{[12]}$. The Langumuir adsorption is characterized by solid layer surface ${ }^{[21]}$.

The adsorption process of organic matter is mainly surface adsorption. The adsorption process of PCB28 by PC and TG showed the distribution of PCB28 to 2 kinds of lipids and the surface adsorption of lipid substances. The distributional effect is occupied the dominant position in the adsorption process ${ }^{[16]}$.

\subsubsection{Bio adsorption}

The removal mechanism of PCBs by the inactivated bacteria is biological adsorption. Biodegradation remains stable in $24 \mathrm{~h}$. The removal rate of sterilization is consistent with the adsorption rate of bacteria. It illustrates that the biological adsorption is the only way to do. With the treatment of live bacteria, biological adsorption and biodegradation of live bacteria exist at the same time ${ }^{[12,30]}$.

\subsubsection{Reversible adsorption and irreversible adsorption}

The adsorption is divided into two parts. One part is linear reversible adsorption, the other part is the irreversible adsorption of Langmuir adsorption isotherm. It comprehensively reflects the internal connection between the various factors of the 
adsorption equilibrium. When organic carbon content is low in soils, the adsorption is linear. Along with the increase of organic carbon content, the isotherm gradually shows nonlinear. So either single equation of Langmuir or Freundlich could not explain the adsorption behaviors of PCBs well ${ }^{[29]}$.

\subsubsection{Fast adsorption and slow adsorption}

The fast adsorption stage is related to the properties of the PCBs and the number of surface active sites of the adsorbent. The slow adsorption is mainly related to the arrangement of the internal active sites of PCBs in the adsorbent. At the initial stage of adsorption, the surface active sites of the adsorbent are more active, and the solute concentration around the active site is also higher. The driving force of the solute is also relatively large. At the same time, the biphenyl ortho carbon hydrogen was not replaced by chlorine atoms. It reduces the steric hindrance of the combination of the binding of the binding agent with the adsorbent, and they are more likely to form Van der Waals force. Hydrophobic molecules are more likely to be assigned to the adsorbent molecules, so the adsorption rate is relatively fast. Accompany the adsorption, the active sites of the adsorbent surface are gradually saturated, and the arrangements of the surface of the adsorbent are gradually stable. The adsorption reaction of biphenyl is diffusion adsorption in the interior of the adsorbed molecules. Compared with the initial stage, the velocity and intensity of surface adsorption both decrease, and it change into enter the slow adsorption stage $^{[26,27,28]}$.

\subsection{Influencing factors}

\subsubsection{The $\mathrm{pH}$ value}

The adsorption rate decreases with the increase of $\mathrm{pH}$ value, and then gradually shows stable. The optimal $\mathrm{pH}$ value is 6 , and at this time the adsorption rate is $56.17 \%$. Because $\mathrm{pH}$ may be one of the important factors that affect the biological adsorption. The $\mathrm{pH}$ value influences the adsorption mainly via the change of the adsorption adsorbent and the surface electrical property, which affects the electrostatic interaction between them ${ }^{[12,27]}$.

The change of $\mathrm{pH}$ in the aqueous phase can affect the configuration of the sediment particles and the existing forms of PCBs, which affects the interaction between PCBs and sediment. When the $\mathrm{pH}$ value is relatively low, small molecule organic matter combines into larger aggregates due to the role of organic matter and mineral surface oxygen bond. So the adsorption of PCBs enhanced. With increase of $\mathrm{pH}$ value, the organic polymer is destroyed, hydrophobic sites disappear, and the affinity of PCBs in sediment release to the aqueous phase, making adsorption capacity decrease ${ }^{[23]}$.

In the presence of HA (humic acid), the adsorption capacity of the PCBs by bological carbon is greatly enhanced. With the increase of HA concentration, the solubility of PCBs also increase. The mechanism of the adsorption is mainly due to the change the electrical property between the surface of the PCB and the adsorbent, resulting in the effect of the electrostatic interaction between them ${ }^{[27]}$. The wheat straw biochar has stronger adsorption force than pine biochar. The causes of the above phenomena are some kinetic and equilibrium adsorption characteristics induced by the chemical heterogeneity of HA.)The adsorption of HA or PCBs by biochars may be due to hydrophobic or Van der Waals' interactions ${ }^{[31]}$. These results are consistent with previous studies ${ }^{[32,33]}$. The presence of HA reduced the $\mathrm{pH}$ value of the solution, and the HA is absent after the adsorption equilibrium of PCBs. This may be due to the intrinsic acidity and the buffering capacity of 
$\mathrm{HA}^{[34]}$.

\subsubsection{Ash}

The value of looks increased with the increase of ash content in soil.

The ash content increased the adsorption capacity of PCBs.

\subsubsection{Organic Matter Content}

The adsorption capacity of PCBs positively correlated with the amount of organic matter in the soil ${ }^{[10,20,8,23,28]}$. And higher the organic matter content, faster the adsorption rate. When the content of organic matter in soil is more than $0.1 \%$, the adsorption process of organic matter is mainly influenced by the content of organic matter in soil. When the content of organic carbon is high, the distribution mechanism plays a major role. When the content of organic carbon is relatively low, the microstructure of the particles plays a major role ${ }^{[35]}$.

\subsubsection{Molecular Size of PCBs}

The molecular size of PCBs is the main reason for the adsorption of PCBs by clay minerals. When the number of chlorine atoms increases, its molecular volume increases and the potential changes of the top and the side surface of the molecules will be caused, which will affect the adsorption ${ }^{[11]}$. As the number of chlorine atoms of PCBs increases, its molecular volume increases, induce the potential changes of the molecules of the top and the side surface, and then affect the adsorption. The HA solubilization effect of high chlorinated PCBs was more obvious. The hydrophobicity of PCBs is mainly related to the number of chlorine atoms connected to PCBs. The more chlorine atoms are connected, the more hydrophobic the water is, Thus the trend of combining with organic and will be more obvious ${ }^{[27]}$. The more the connected chlorine atoms, the more hydrophobic the PCBs. Thus the trend of combining with organic phase will be more obvious ${ }^{[27]}$.

\subsubsection{Adsorbent ( Carbon Chain Length, Pore Size, Oxygen Functional Groups, Particle Size )}

The isothermal adsorption of PC and TG on PCB28 was expressed as the distribution process of PCB28 in 2 lipids. The adsorption capacity of PC to PCB28 was stronger than TG. The length of fatty acid carbon chain may be the main reason for the influence of the adsorption mechanism of lipid substances ${ }^{[16]}$.

The rate of four kinds of activated carbon adsorption of PCBs is similar to their average pore size and the size of the functional groups of activated carbon, which shows that the adsorption effect is closely related to the oxygen functional groups, pore volume and surface area of the adsorbent. PCBs are mainly in the microspore of adsorbent and suffer multiple physical adsorption of the wall of the hole.

The smaller the particle size, the stronger the adsorption capacity of PCBs .The greater the particle size, the weaker the adsorption capacity of PCBs. Probably because the larger the particle size, the higher the content of organic carbon ${ }^{[28,36,37]}$. 


\subsubsection{Ratio of solid to liquid}

With the increase of the ratio of solid to liquid, the adsorption capacity of two kinds of paddy soil on PCBs decreased. The main reason is that the contact area between the adsorbent and the PCB reduced, which leads to the decrease of unit adsorption capacity.

\subsubsection{Temperature}

The effects of temperature on the adsorption process include two processes. One is that the temperature changes the dispersion coefficient, which affects the degree of adsorption. The other is that the temperature has a direct relationship to the diffusion of solute in solution and pore water ${ }^{[38]}$.

When the temperature changes, the surface adsorption activity and water solubility of PCBs will change, and affect the adsorption performance of PCBs. The adsorption capacity decreases slightly with the increase of temperature. The reason may be that the increase of the temperature leads to the raise of water soluble of PCBs ${ }^{[39-44]}$, while reducing the PCBs adsorption partition coefficient in soil. It can be deduced that the adsorption of PCBs on paddy soil is likely to be an exothermic process. Akkaya G showed that the adsorption rate increased with the increase of temperature. The reason may be that the adsorption is endothermic process temperature range in this temperature range. The temperature raise is more favorable for the adsorption reaction ${ }^{[45-52]}$.

\subsubsection{Ion Concentration}

When the ionic strength of the solution increased, the adsorption capacity of PCBs decreased. The reasons are as follows:

The phenomenon of salting out exists in electrolyte solution, that is ion concentration increasing, dissolved organic matter content decreasing, adsorption competition between dissolved organic matter and cation will reduce the adsorption of particulate matter to organic matter. The ion can occupy some adsorption sites on the particles, then competes with PCBs on adsorption; The ionic strength increasing will compress the double layer and weakens the electrostatic interaction between the PCB and the adsorbent, which is not conducive to the adsorption of PCBs. With the increase of cation concentration, organic matter exists in the "closed" structure, which weakens the affinity of PCBs ${ }^{[16,23]}$.

\subsubsection{The Content of Clay}

If the clay content higher, soil particle size is smaller and the soil adsorption capacity of $\mathrm{PCBs}$ is stronger.

\section{Conclusions}

By studying the adsorption mechanism and the influencing factors of PCBs, it is helpful to study the environmental chemical behavior of PCBs, and to better understand the migration and transformation law of PCBs. It is of great significance to provide theoretical basis for the establishment of PCBs migration and transformation model, which is of great significance for the management and control of environmental pollution, and thus provides a reliable scientific basis for the management of persistent organic pollutants in China. 


\section{Outlook}

4.1 Getting more types of adsorbents and adsorption data of soil to PCBs is necessary.

4.2The adsorption and desorption process are actually carried out at the same time. Therefore, it is needed to further study on the desorption behavior of PCBs.

4.3 Quantifying different influence factors on the adsorption of PCBs.

4.4 Strengthening dynamic, field, composite research. The researches on the multi components are lesser; The experimental will focus on the complex field situation.

4.5 Going deep into studying on organic matter and having a quantitative description of the effects of organic matter on Adsorption Behavior.

4.6 The researchers put forward a number of relevant theories and models, but these theories and models are not universally applicable. We need to further study the adsorption behavior of PCBs in mechanism.

\section{Acknowledgement}

Project supported by the Science and technology development fund of Higher Education foundation from the Education Commission of Tianjin, China (Grant mumber20130518.).

\section{References}

1. Li Y, Harner T, Liu L, et al, Polychlorinated biphenyls in global air and surface soil : distributions, air-soil exchange, and fractionation effect. Environ Sci Technol. 44 (2010) 2784-2790.

2. WHITFIELD ASLUND M L, RUTTER A, REIMER K J, etal, The effects of repeated planting, and specific tranfer pathways on PCB uptake by cucurbita pepo grown in field conditions .Science of the Total Environment. 1/3 (2008) 14-25.

3. Breivik K, Sweetman A, Pacyna J M, etal .Towards a global historical e-mission inventory for selected PCB congeners mass balance approach: 1.Global production and consumption .Environ Sci Technol. 290 (2002) 181-198.

4. Meijer S N, Ockenden W A, Sweetman A, et al, Global distribution and budget of PCBs and HCB in background surface soils: implications for sources and environmental process. Environ Sci Technol. 37 (2003) 667- 672.

5. Meng Qingyu, storage Shaogang, Xiaobai, Polychlorinated biphenyls (PCBs) of the progress in the research on adsorption behavior of environment .Science Bulletin. 45 (2000) 1572-1583.

6. ChuSG, CaiML, XuXB, Soil-plant transfer of polychlorinated biphenyls in paddy fields. Environ Sci Technol. 234 (1999) 119-126.

7. Cornelissen G, Rigterink H, Ferdinandy M A, et al, Rapidly desorbing fractions of PAHs in contaminated sediments as a predictor of the extent of bioremediation . Environ Sci Technol.32 (1998) 966-970.

8. TAN Liqiang, FENG Liangdong, Research on Adsorption of Plasma Modified Grafting Attapulgite with Chitosan on Waste Liquid Containing 4,4'-Dichlorobiphenyl.Coal and Chemical Industry. 36 (2013) 45-48.

9. GAO Jun1,2, LUO Yongming1, Effects of Crop Ashes on Adsorption of PCBs to Agr icultural Soil Measured by POM- SPE .Journal of Agro-Environment Science .25 (2006) 1217- 1220.

10. CUI Zhaojie1*, SONG Shanjun1, LIU Jing2, PCBs adsorption to soils: Isotherm modeling and influencing factors .Ecology and Environmental Sciences. 19 (2010) 325-329.

11. CHEN Tao1, SUN Chengxun1, CHEN Weiwei, Effects of surfactants on the absorption 
of PCBs on soil, Environmental Pollution and Pontrol. 35 (2013) 59-64.

12. CHEN Xiong, WEI Yiyang, LI Huixin, LIANG Mingxiang, XU Li, Biosorption and biodegradation mechanisms of trichlorobiphenyl by Ensifer adhaerens. China Environmental Science, 35 (2015) 1423-1428.

13. Wang Shaoyan, PCBs soil pollution risk and soil pollution adsorption mechanism research .Zhejiang: Zhejiang University. (2006) 21-44.

14. Xiongyuan, Nano materials on PCB77 adsorption and degradation of . Anhui: Anhui Agriculture University. (2011) 17-42.

15. LIU Gang, LIU Zongtang, DENG Quan1, YANG Yong1, ZHANG Gangya2, WANG Guozhong1, Kinetics of adsorption of PCB-77 on micro/nanostrutureed hollow $\mathrm{Fe}_{3} \mathrm{O}_{4}$ spheres .The 2011 and the sixth session of the persistent organic pollutants forum .270-27.

16. SUN Xianghuil, TENG Ying, LUO Yongming, Sorption Behavior of PCB28 to Phosphatidylcholine and Triglyceride. ENVIRONMENTAL SCIENCE, 31 (2010) 2327-2330.

17. Zhou Yufeng, Jiang Lina, Zhang Jianying, Comparison of the adsorption behavior of PCBs in paddy soils .Journal of soil, 49 (2012) 184-188.

18. SI Xiongyuan, WANG Yin, CHEN Qian- qian, Adsorption Charcteristics of PCBs in Soils and Clay Minerals. Chinese Journal of Soil Science, 43 (2012) 315-319.

19. TAN Liqiang, JIANG Jinlong, FENG Liangdong, Kinetic and Thermodynamic Study on the Removal of Aqueous Polychlorinated Biphenyl by Plasma Induced Grafting Attapulgite . Journal of Huaiyin Institute of Technology, 22 (2013) 1-6.

20. CHEN Tao, SUN Chengxun, YANG Xiaoying, Adsorption of PCBs onto main componnents in soil and effect of coexistent $\mathrm{Cu}^{2+}$. Journal of China University of Minning \& Technology, 41 (2012) 821-826.

21. Qu Qiyun, Preparation of $/ \mathrm{TiO}_{2}$ nanoparticles composite and its adsorption on . PCBs Journal of HeFei University of Technology (NATURAL SCIENCE EDITION). 36 (2013) 748-754.

22. Song Shanjun, Cui Zhaojie, Study on the adsorption kinetics and thermodynamics of typical PCBs in soils. Shandong: Shandong University, (2010) 21-41.

23. Sebald w, Yellow River tou Dao Guai section of the PCBs distribution characteristics and adsorption mechanism. Inner Mongolia, Inner Mongolia Agricultural University. (2012) 15-48.

24. Zhou Yufeng, Study on the adsorption mechanism of PCBs in three representative soils. Zhejiang: Zhejiang University, (2011) 25-56.

25. MAOShi-hui, GUO Xinchao, ZHOU Yanmei, Sorption Kinetics and Adsorption/Desorption of Tetraachlorobiphenyl onto Plant Ash. Environmental Science \& Technology, 36 (2013) 42-46.

26. PENG Wei1, FANG Zhendong2, QIAO Hua3, SHI Yonggang2, HAO Quanlong1, Study on Sorption Kinetics of 3,3',4,4'-tetrachlorobiphenyl onto Humic Acid. SICHUAN ENVI R ONMENT, 34 (2015) 18-24.

27. Zhang Haibo, Study on the adsorption properties and main influencing factors of PCBs in water by powdered activated carbon. Harbin: Harbin Institute of Technology, (2011) 13-50.

28. Wang Peiyun, Study on the adsorption kinetics and retardation factor of the persistent organic matter, ten of.in Xi'an: Chang'an University, (2014) 11-42.

29. BI Xinhui, CHU Shaogang, XU Xiaobai, The adsorption behavior of polychlorinated biphenyls (PCBs) in soil. China Environmental Science, 21 (2001) 284-288.

30. Ding J, Chen B L, Zhu L Z, Biosorption and biodegradation of polycyclic aromatic hydrocarbons by Phanerochaete chrysosporium in aqueous Solution. Chin Sci Bull. 57 (2012) 2276-2284. 
31. Yu Wang, Lei Wang, Guodong Fang, Enhanced PCBs sorption on biochars as affected by environmental factors: Humic acid and metal cations. Environmental Pollution.172 (2013)86-93.

32. Koelmans, A.A., Meulman, B., Meijer, T. Attenuation of polychlorinated biphenyls sorption to charcoal by humic acids .Environmental Science \& Technology. 43 (2009) 736-742.

33. Cornelissen, G., Gustafsson, O, Effects of added PAHs and precipitated humic acid coatings on phenanthrene sorption to environmental black carbon .Environmental Pollution. 141 (2006) 526-531.

34. Qiu, Y.P, Xiao, X.Y. Cheng, Influence of environmental factors on pesticide adsorption by black carbon: $\mathrm{pH}$ and model dissolved organic matter .Environmental Science \& Technology. 43 (2009) 4 973-4978.

35. Chiou C T, Porter P E, Sehmedding DW, Partition equilibria of nonionic organic matter and water. Environ Sci Technol. 17 (1983) 227-231.

36. Kariekhoff S.W., Brown D. S., Scott T.A, Sorption of hydrophobic pollutants on natural sediments .Water Researeh. 13 (1979) 241-248.

37. Chin Y.P, Webber W.J.Jr, Estimating the effects of dispersed organic polymers on the sorption of contaminants by natural solids.1.A Predictive thermodynamic humic substance-organic solute interaction model. Environ Sci Technol. 23 (1989) 978-984.

38. Wu S C, Gsehwend P M.SorPtion, kineties of hydrophobic organic compounds to natural sediments and soils. Environ Sci Technol, 20 (1986) 717-725.

39. Akkaya G, Ozer A. Biosorption of Acid, Red 274 (AR274) on Dicranella varia: Determination of equilibrium and kinetie model Parameters. Proeess Biochem. 40 (2005) 3559-3568.

40. Filius J D, Lumsdom D G, Meeussen J C L, etal, Adsorption of Fulvic Acid on Goethite. Geochim Cosmochim AC. 64 (2000) 51-60.

41. NORTHCOTT G L, KEVIN C J, Partitioning, extractability and formation of nonextractable $\mathrm{PAH}$ residues in soil.1.compound differences in aging and sequestration .Environmental Science \& Technology. 35 (2001) 1103-1110.

42. Yonghong, Yue Lixia, leaf Fabing, $\mathrm{Zn}^{2+}$ to iron oxides absorption attached bensulfuron methyl .Journal of safety and environment. 6 (2006) 20-22.

43. Yu Wang, Lei Wang, Guodong Fang, Enhanced PCBs sorption on biochars as affected by environmental factors: Humic acid and metal cations .Environmental Pollution. 172 (2013) 86-93.

44. Polo, M.S., Utrilla, J.R., Adsorbents interactions in the adsorption of Cd (II) and Hg (II) on ozonized activated carbons .Environmental Science \& Technology. 36 (2002) 3850-3854.

45. Qu, X.L., Liu, P., Zhu, D.Q.. Enhanced sorption of polycyclic aromatic hydrocarbons to tetra-alkyl ammonium modified smectites via cation-p interactions .Environmental Science \& Technology. 42 (2008) 1109-1116.

46. Chen, J.Y., Zhu, D.Q., Sun, C, Effect of heavy metals on the sorption of hydrophobic organic compounds to wood charcoal .Environmental Science \& Technology. 41 (2007) 2536-2541.

47. Chen, J.Y., Zhu, D.Q., Sun, C., Effect of heavy metals on the sorption of hydrophobic organic compounds to wood charcoal .Environmental Science \& Technology. 41 (2007) 2536-2541.

48. Uchimiya, M., Lima, I.M., Klasson, K.T., Chang, S.C., Immobilization of heavy metal ions (Cu-II, Cd-II, Ni-II, and Pb-II) by broiler litter-derived biochars in water and soil .Journal of Agricultural and Food Chemistry. 58 (2010) 5538-5544.

49. Agblevor, F.A., Beis, S., Kim, S.S., Biocrude soils from the fast pyrolysis of poultry litter and hardwood .Waste Management. 30 (2010) 298-307. 
50. Ioannidou, O.A., Zabaniotou, A.A., Stavropoulos, G.G., Preparation of activated carbons from agricultural residues for pesticide adsorption .Chemosphere. 80 (2010) 1328-1336.

51. LIU Yonghong, YUE Xiali, YE Fabing, et al, Effect of $\mathrm{Zn}^{2+}$ on bensulfuron-methyl adsorption in iron oxides .Journal of Safety and Environment. 6 (2006) 20-22.

52. Rheinlander T, KlumPP E, Sehwuger M J, On the adsorption of hydrophobic Pollutants on surfac/clay complexes: comparison of the influence of cationic and a nonionic surfactant .J DisPersion Science and Technology. 19 (1998) 379-398. 